\title{
Ética e formação profissional: uma leitura da produção científica em Ciência da Informação (1970-2006)
}

\author{
Ethics in relation to the professional education in the field of \\ Information Science (1970-2006)
}

\author{
Leilah Santiago BUFREM' \\ Sônia Maria BREDA² \\ Tidra Viana SORRIBAS ${ }^{3}$ \\ Juliana Lazzarotto FREITAS ${ }^{4}$
}

\section{RESUMO}

Analisa a figura da ética relacionada à formação profissional em informação. Aponta aspectos e questões evidenciados em análise de conteúdo da presença temática da ética expressa na literatura periódica em ciência da informação. Parte de um levantamento de artigos de periódicos, registrado em base de dados específica (BRAPCI), relativa ao período entre 1970 e 2006, composta de um total de 4212 artigos, publicados em 26 títulos. Após extração de um corpus, constituído de 37 artigos, procedentes de 16 títulos, revela as tendências investigativas sobre o tema, a fim de evidenciar como tem sido enfocada a ética e suas relações com a formação do profissional da informação, as temáticas a ela associadas e as principais questões levantadas pelos autores dos artigos. $O$ conjunto de artigos selecionados foi analisado também pela freqüência dos descritores, periódicos de origem e ano de publicação. Registra a baixa ocorrência de discussões relativas à ética e sua importância para a formação dos profissionais da informação. Constata ainda a variedade de olhares para esse objeto, enfatizando sua relevância como elemento-chave da educação e do preparo de sujeitos para o mundo do trabalho.

Palavras-chave: ética e educação; ética e formação profissional; formação profissional em Ciência da Informação.

\footnotetext{
ABSTRACT

It analyses ethics in relation to the professional education in the field of Information Science. It points out main aspects and questions of the matter as a result of a content analysis on ethics thematic presence in Information Science periodic literature. The starting point is an article survey in a specific database (BRAPCI), period 19702006, which includes 4212 articles, published by 26 periodicals. The corpus obtained consists of 39 articles from 16 periodicals. Research trends are revealed in order to give evidence of ethics and the education of information professionals approach, as well as related matters and main questions introduced by the authors. Describers'

1 Professora Titular, Departamento de Ciência e Gestão da Informação, Universidade Federal do Paraná. Alameda Cabral, 410 , Centro, 80410-210,Curitiba,PR, Brasil. Correspondência para/Correspondence to: E-mail:<leilah@ufpr.br>.

2 Professora Assistente, Departamento de Ciência e Gestão da Informação, Universidade Federal do Paraná. Curitiba, PR. E-mail: $<$ breda@ufpr.br>.

3 Bolsista de Iniciação Científica (PIBIC/CNPq), Graduanda, Curso de Gestão da Informação, Universidade Federal do Paraná. Curitiba, PR, Brasil. E-mail: <tidra@ufpr.br>.

4 Bolsista de Iniciação Científica (PIBIC/CNPq), Graduanda, Curso de Gestão da Informação, Universidade Federal do Paraná. Curitiba, PR, Brasil. E-mail: <ju.lazzarotto@yahoo.com.br>.

Recebido em 16/5/2007 e aceito para publicação em 28/1 1/2007.
} 
frequency, periodic of origin and year of publication are also analyzed. It reports the low occurrence of discussions about ethics and its importance for the education of professionals. It still shows the variety of points of view on this question, and emphasizes ethics relevance for education and citizen's formation for labor world.

Keywords: ethics and education; ethics and professional education; Information Science education.

\section{INTRODUÇÃO}

A questão ética desponta como uma das mais atuais problemáticas no contexto político-econômico, social e cultural, entretanto merecem especial destaque suas relações com o campo da formação profissional. Leituras assistemáticas fornecem um retrato de múltiplas abordagens e tratamentos dados ao binômio "ética e educação", sugerindo que nunca se discutiu tanto ética como agora. Aponta-se para essa excessiva preocupação com o tema, como se esse fosse novo produto de consumo no mercado das idéias.

No amplo debate sobre a questão, são apontados mecanismos de poder econômico e político dispostos a esvaziar as formas tradicionais de resistência e, sobretudo, os meios de manipulação simbólica das consciências, que tendem a reduzi-las à sua dimensão positiva, legitimadora do status quo. Camuflando a massificação dos pensamentos e dos desejos na valorização exacerbada da personalidade livre, autêntica e única, a indústria cultural torna-se cada vez mais efetiva nas sociedades "pós-modernas", contribuindo para enfraquecer a reflexão crítica e o desejo utópico da razão humana, fundamentais na construção histórica da autodeterminação.

Reforça a precariedade do contexto a criação de

[...] um novo paradigma de produção industrial, a "automação flexível", possibilitado pela revolução tecnológica que transformou a ciência e a tecnologia em forças produtivas, agentes da própria acumulação do capital, fazendo crescer enormemente a produtividade do trabalho humano (Oliveira, 1996, p. 165). social e moral universalmente válida diante dos diversos interesses que afloram na atual sociedade. O empenho em superar o fundamento individualista desse ideário desloca-se, hoje, para o terreno da investigação e ação éticas, em defesa da vida.

A denúncia de McLaren (1997, p. 266), por outro lado, aponta o abandono do projeto de engajamento político e de possibilidades humanas, tanto por parte de educadores, quanto de críticos profissionais que "promoveram o desespero às custas de analisar as relações fundamentais do poder que caracterizam as formas existentes de hegemonia cultural e política." Ao alijarem a "consideração pelas realidades do sofrimento, dor e tortura [...] em favor do domínio de técnicas de aprendizagem e do currículo", os esforços atuais de reformas indicam falta de vontade de "construir e sustentar um projeto político claramente articulado, no qual a pedagogia possa ser relacionada à criação de práticas educacionais e referentes morais necessários para a construção de uma esfera pública democrática" (McLaren, 1997, p.266).

A ética impõe-se, pois, como presença inegociável na educação superior, ante-sala do exerć́cio profissional. Particularmente no campo da ciência da informação, dada a natureza de seu objeto de estudo e trabalho, a ética permeia todos os poros do acesso, "posse" e uso da informação como bem essencial à sobrevida na sociedade contemporânea, direito de todos, condição de cidadania - seja na seara acadêmica, seja no tempo/espaço da atuação laboral. No contexto de uma sociedade "globalizada", a ética merece especial atenção na interpretação de seus contornos e movimentos.

O presente texto resulta da análise e interpretação de aspectos e questões mais relevantes evidenciados em análise de conteúdo sobre a presença temática da ética relacionada com a formação profissional, expressa na literatura periódica em ciência da informação, no período de 1970 a 2006 . Revela as tendências investigativas nesse campo, a fim de 
demonstrar como tem sido enfocada a ética e suas relações com essa educação superior profissionalizante, as temáticas a ela relacionadas e as principais questões levantadas pelos autores dos artigos, assim como outras marcas dessa produção. A busca é motivada pela expectativa de que o tema se mostre visível na literatura, como representação de uma presença curricular e acadêmica ao longo da formação de bibliotecários, documentalistas, arquivistas, museólogos, gestores e outros profissionais da informação.

\section{A ÉTICA E O CONTEXTO}

Como um objeto simultaneamente estável e sensível às vibrações do contexto - econômico, sobretudo -, em que se pratica, a ética constitui-se em tema que impõe reflexões sobre o processo de construção do conhecimento e das práticas a ela relacionadas, especialmente em ambiente universitário. Em última instância, é esse ambiente de renovação pela crítica que, de forma privilegiada, coloca o homem diante de sua condição, como responsável pelo mundo e pela sua existência.

Isso porque as transformações provocadas pela revolução tecnológica influenciaram não só os métodos de trabalho, como as relações sociais de produção. Assim, as chances apresentadas por essas transformações podem tornar-se sedutoras, diante de uma vida satisfatória do ponto de vista da realização dos indivíduos. Como afirma Schaff (1993), há também que se reconhecerem os riscos de convivência entre opulência e totalitarismo exercido pela riqueza material.

Alertando para o paradoxo do progresso que se alimenta do atraso, Dupas (2001, p.69) analisa os contrastes da sociedade contemporânea e propõe como saída a "ética da responsabilidade", capaz de construir uma convivência para impedir o triunfo da barbárie, uma vez que "os imensos custos sociais acarretados pela mudança nos padrões tecnológicos aparecem como inevitáveis".

Em sua introdução ao ensaio sobre a ética, Badiou (1995) recupera o que essa parte da filosofia representou para os filósofos, referindo-se inicialmente aos estóicos, que a elegeram o cerne de sua filosofia. O sábio seria aquele que, organizando as coisas entre as que dependem e as que não dependem dele, organizaria sua vontade em prol das primeiras, suportando impassivelmente as segundas. Os modernos, para os quais o sujeito é central, a partir do pensamento cartesiano, consideravam a ética sinônimo de moralidade, ou de razão, na visão kantiana. A distinção, embora sutil, entre ética e moralidade, devese a Hegel, que reserva o princípio ético à ação imediata, enquanto a moralidade refere-se à ação refletida. $O$ atual retorno à ética toma a palavra num sentido mais próximo de Kant (ética do juízo) do que de Hegel (ética da decisão), segundo Badiou (1995, p. 16), para quem a ética designa hoje um princípio de relação com "o que se passa". Num primeiro momento, o autor examina a natureza do fenômeno, tentando mostrar que, como tendência filosófica do momento, é na verdade um niilismo. Já no segundo momento, dá um sentido diverso à palavra ética, negando-se a vinculá-la a categorias abstratas, mas referindo-a a "situações" e reconstruindo o que ele considera um "conceito admissível de ética, que subordina sua máxima ao devir das verdades" (Badion, 1995, p. 98).

Mais ou menos otimistas, convencionais ou não convencionais, sejam quais forem as correntes responsáveis pela atual construção de conhecimentos sobre a ética, as análises conduzem a inquietações, especialmente se considerada a aparente perda de controle da sociedade sobre o saber científico que se produz em instituições de ensino e pesquisa.

Do ponto de vista da produção científica específica sobre o tema, para a qual se inclina este estudo, reafirma-se a crença de que um objeto de conhecimento se constrói na medida em que os estudiosos contribuem com sua crítica para sua inserção em determinado campo científico.

\section{O PROCESSO DE ANÁLISE}

Este trabalho teve como foco a presença do tema ética na literatura periódica em ciência da informação. Parte de um levantamento de artigos de periódicos, registrados em base de dados específica (BRAPCl),

\footnotetext{
${ }^{5}$ Base de Dados Referenciais de Periódicos Nacionais da Área de Ciência da Informação.
} 
relativa ao período entre 1970 e 2006, composta de um total de 4212 artigos, publicados em 26 títulos ${ }^{6}$. Considerando-se como foco de interesse e busca os artigos representativos da presença temática da ética nessa produção, extraiu-se um corpus de 37 artigos, oriundo de 16 títulos de periódicos, a partir da recuperação dos termos "ética" e "moral" constantes dos títulos, das palavras-chave e/ou dos resumos.

A base de dados BRAPCI utiliza-se do software ProCite, versão 5.0 do Institute for Scientific Information. Trata-se de um programa para armazenamento de dados referenciais projetado para o ambiente Windows e Macintosh. A análise bibliométrica das referências e resumos incorporados na base proporciona a identificação para posterior estudo e caracterização dos artigos publicados.

O conjunto de artigos selecionados para este estudo foi analisado do ponto de vista das tendências temáticas, da freqüência dos descritores, dos títulos dos periódicos de origem e do ano de produção. As categorias temáticas foram definidas a posteriori, devido à diversidade decorrente da procedência editorial, própria de um campo interdisciplinar por natureza. Considerando a dispersão da autoria (37 artigos do corpus foram produzidos por 49 autores) e a dispersão por localização geográfica das revistas relacionadas, essas relações foram desconsideradas na análise.

\section{ÉTICA NA LITERATURA EM CIÊNCIA DA INFORMAÇÃO}

As principais tendências temáticas observadas no corpus, conforme Figura 1, são: ética profissional (nove artigos); ética e conhecimento científico (oito); ética e tecnologias (seis); ética - aspectos teóricos (quatro); ética e direito à informação (quatro); ética nas organizações (três); ética e direito autoral (três); ética e trabalho (três); ética e políticas de informação (três).

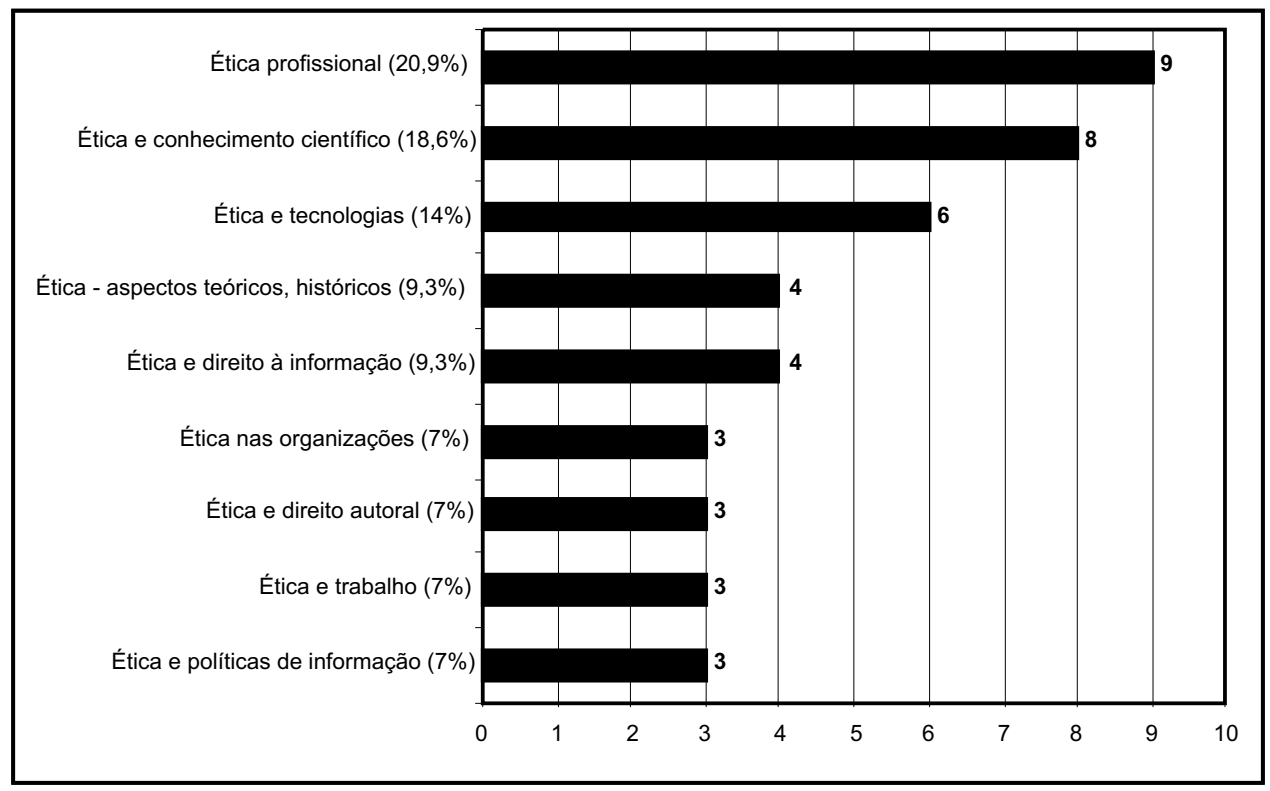

Figura 1. Relação de artigos por categoria temática. Fonte: As autoras, de acordo com Base BRAPCI.

\footnotetext{
${ }^{6}$ Arquivística.net; Arquivo \&Administração; BIBLOS: Revista do Departamento de Biblioteconomia e História; Cadernos de Biblioteconomia; Ciência da Informação; Comunicação \& Informação; DataGramaZero; Em Questão: Revista da Faculdade de Biblioteconomia e Comunicação da UFRGS; Encontros Bibli; Estudos Avançados em Biblioteconomia e Ciência da Informação; ETD - Educação Temática Digital; Infociência; Informação \& Informação; Informação \& Sociedade: Estudos; Informare - Cadernos do Programa de Pós-Graduação em Ciência da Informação; Liinc em revista; Perspectivas em Ciência da Informação; Revista ACB: Biblioteconomia em Santa Catarina; Revista Brasileira de Biblioteconomia e Documentação; Revista da Escola de Biblioteconomia da UFMG; Revista de Biblioteconomia \& Comunicação; Revista de Biblioteconomia de Brasília; Revista Digital de Biblioteconomia \& Ciência da Informação; Revista do Departamento de Biblioteconomia e História; Revista Online da Biblioteca Prof. Joel Martins; Transinformação.
} 
A análise dos 37 artigos constituintes do corpus deste estudo revela uma produção majoritariamente voltada às questões específicas da formação profissional de bibliotecários, imbricada com preocupações contemporâneas do universo do trabalho.

Esse conjunto de artigos inclui a reflexão sobre o contexto histórico, social ou econômico, denotando a consciência da impossibilidade de dissociar as questões éticas das práticas sociais, e evidenciando a configuração sui generis da ética como propulsora e definidora da ação humana, que transforma e se deixa transformar enquanto adianta a história, assim se redefinindo a própria ética.

O debate sobre o advento do paradigma digital contribui para a formulação de um novo projeto ético no domínio científico, o que fica patente nos artigos relacionados às questões da ciência, produção e comunicação do conhecimento. Em análise abrangente, pode-se visualizar a preocupação com as contradições da inovação tecnológica e suas influências nas relações de força presentes no contexto profissional e na conjuntura social mais ampla, o que de certo modo coincide com a análise de Dupas (2001).

Comparecem em três artigos os usuários ou clientes cuja visibilidade na produção científica da área de informação usualmente mostra-se abaixo de seu grau de importância. Nesses textos, sobressai a discussão sobre o significado das relações entre homem e tecnologia e as complexas implicações desses liames no mundo brutalmente competitivo. Elemento privilegiado em um quarto artigo, a valorização do homem adentra o debate, insistindo-se que deve o humano prevalecer sobre os ditames do lucro e da funcionalidade. As linhas determinantes para a leitura desses artigos representam os componentes da dimensão político-econômica neoliberal, especialmente as formações produtivas: inovações tecnológicas e organizacionais, consideradas por Alves (1996) como a ofensiva do capital na produção.

A ética associada à pesquisa e à produção científica está presente em cinco artigos. Neles se evidencia o compromisso da ética com os saberes, com sua geração e disseminação, sem deixar de lado as questões relacionadas não somente às tecnologias de produção editorial, como também à avaliação da produção científica e à condução desse processo. Representam, no conjunto analisado, um olhar atento sobre a relação da sociedade com o saber científico produzido.

O interesse pela dimensão prática da ética no cotidiano do trabalhador revela uma forma de abrir o pensar à experiência fundante do trabalho e ao novo, de realizar a crítica à prática, opondo-se ao repetível, ao previsível, ao que sucede sem risco ou incerteza. $\bigcirc$ tom pragmático norteador dessas contribuições reveste a ética de contemporaneidade, sem que se perca a inegociável marca da discussão de sua presença em toda ação humana.

A análise dos 153 descritores levantados no corpus reproduz a dispersão já observada quanto à autoria e distribuição geográfica dos artigos. A superioridade de incidência do termo "ética" (10 menções) e de suas relações diretas (num total de 16 menções) é explicada por representarem o foco da busca neste trabalho.

A distribuição dos artigos pelos 16 periódicos, de acordo com a Figura 2, revela sua maior incidência (24,3\%), com 9 artigos, na revista Ciência da Informação ( $\mathrm{C}$ i. Inf.), título que tem uma publicação regular desde seu fascículo inaugural, em 1972. Em análise de distribuição por periódico, porém, os cuidados de relativização são fundamentais, importando levar em conta outras variáveis além da antiguidade e da freqüência, como a periodicidade e o número médio de artigos por fascículo. O periódico DataGramaZero (DGZ), criado em 1999, desponta dentre os títulos mais dedicados à questão, com incidência de 16,2\%, embora não seja o de maior destaque proporcionalmente ao número de artigos.

Procurando-se facilitar a análise de distribuição dos artigos por revista, foi evidenciada também a relação entre os artigos sobre ética e o total de artigos indexados, relação expressa na Figura 3. Essa representação gráfica confirma a Infociência (Inf.), anteriormente denominada Revista de Biblioteconomia do Maranhão, criada em 1997 e interrompida no período de 1999 a 2002, como a revista que maior percentual apresenta de artigos sobre ética dentre o universo analisado, embora essa representatividade seja de apenas um artigo dentre os quinze publicados, seguindo-se das revistas Em Questão, Biblios e DataGrama Zero.

A distribuição dos artigos por ano de publicação, conforme Figura 4, mostra ausência temática da ética no período anterior a 1976 e visibilidade de incidência 
a partir da segunda metade da década de 1990. $\bigcirc$ ano de 2005 corresponde à maior concentração de artigos (oito), caracterizando um período particularmente marcado pelo debate de novos imperativos éticos, provocado pelas transformações crescentes geradas pela incorporação de novas tecnologias, impondo-se um repensar do homem extensivo à sua dimensão profissional.

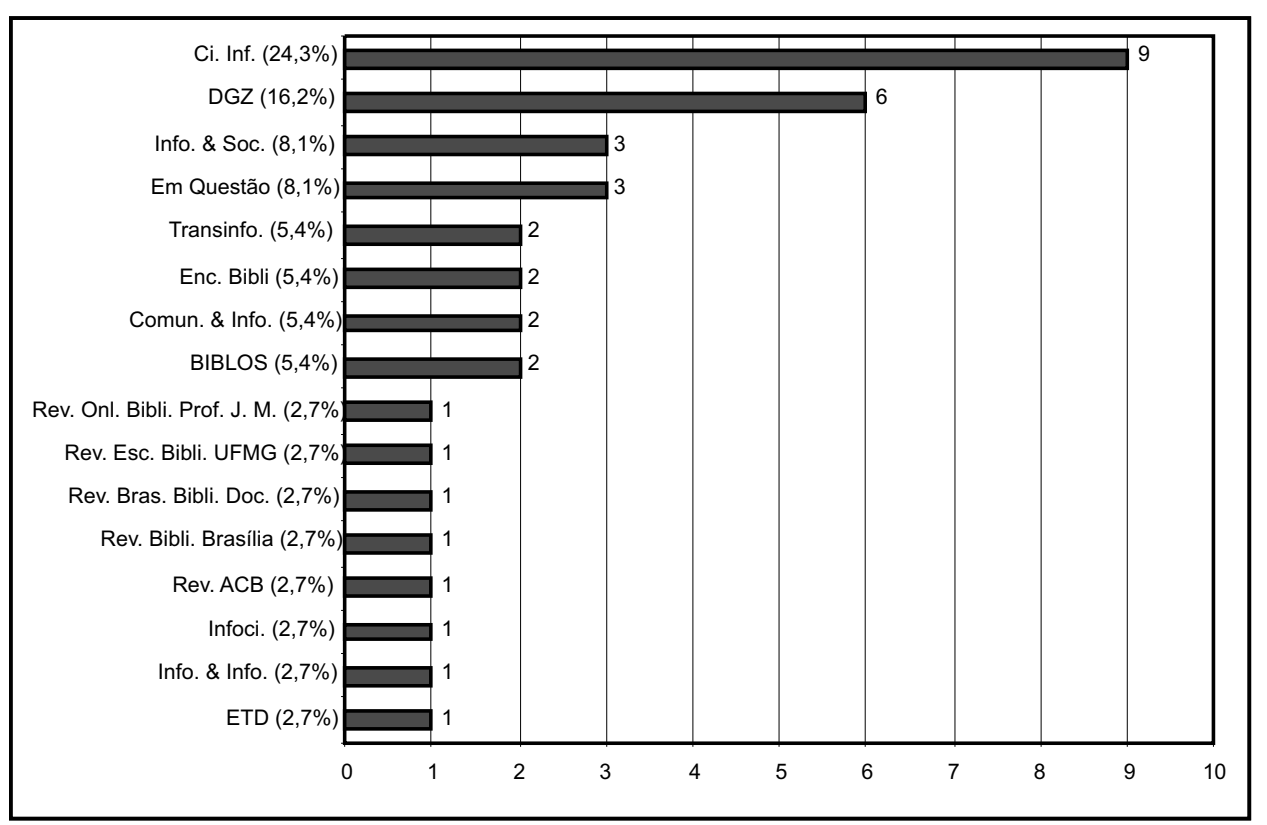

Figura 2. Relação de artigos sobre ética por periódico.

Fonte: As autoras, de acordo com Base BRAPCI.

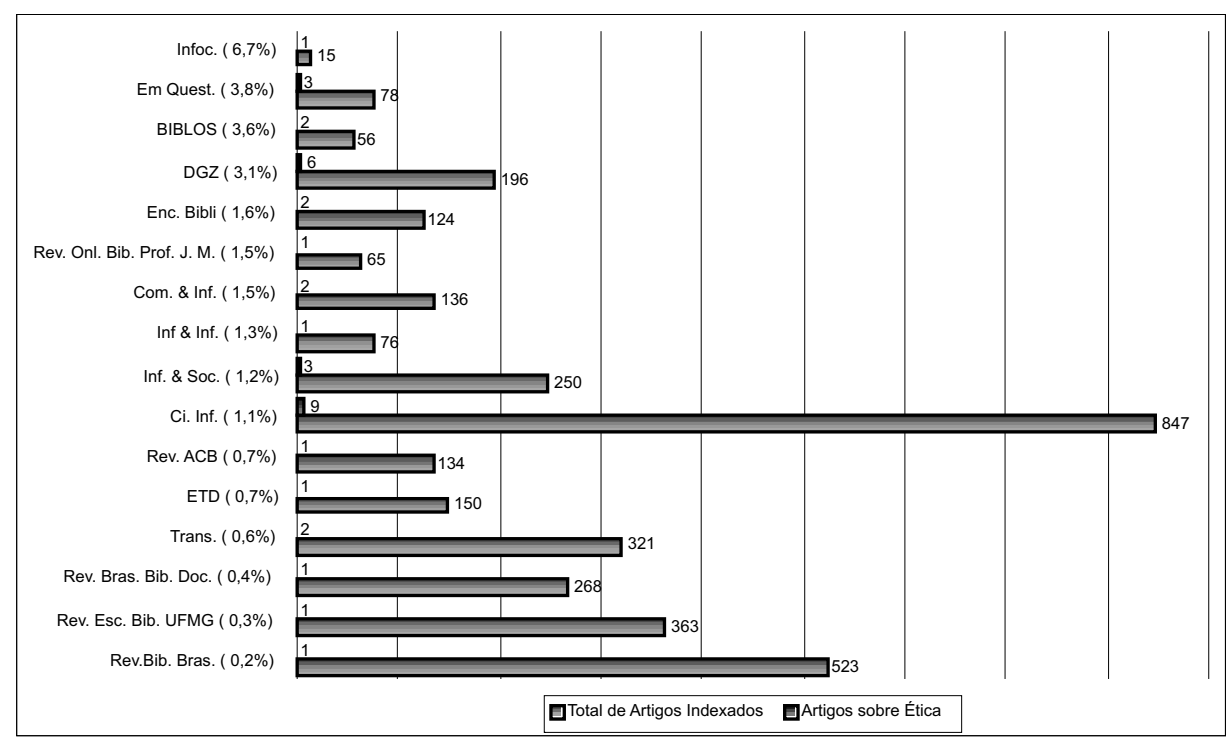

Figura 3. Relação entre artigos sobre ética e total de artigos indexados. Fonte: As autoras, de acordo com Base BRAPCl. 
Essa tendência reflete-se também em eventos da década, tais como VII Encontro Nacional de Acervo Raro (VII ENAR), cujo tema central foi Ética e Responsabilidade Social na Administração de Acervos Raros. Foram enfocados temas como a formação de coleções, o tratamento técnico, a preservação e a guarda de acervos especiais, englobando, ainda, questões como a segurança de acervos e o perfil dos curadores das coleções. Ocorreu também o Encontro Nacional dos Conselhos Profissionais, em Florianópolis, Santa Catarina, reunindo presidentes, dirigentes e técnicos de Conselhos Profissionais de todo o país, que endossaram documento expondo a preocupação do segmento com "a relativização da ética nas Instituições Públicas e Privadas do país".

Destacam-se também, nesse período, dois eventos, o VI e o VII ENANCIB, nos anos de 2005 e 2006, cujo Grupo de Trabalho Política, Ética, e Economia da Informação (GT 5), coordenado pela Profa. Dra. Marta Pinheiro Aun (UFMG), contribuiu de modo significativo para os estudos desse domínio, sob temas relativos a Políiticas públicas de informação, Economia da informação e da comunicação, Política científica e tecnológica, Ética e Informação e Inclusão informacional.

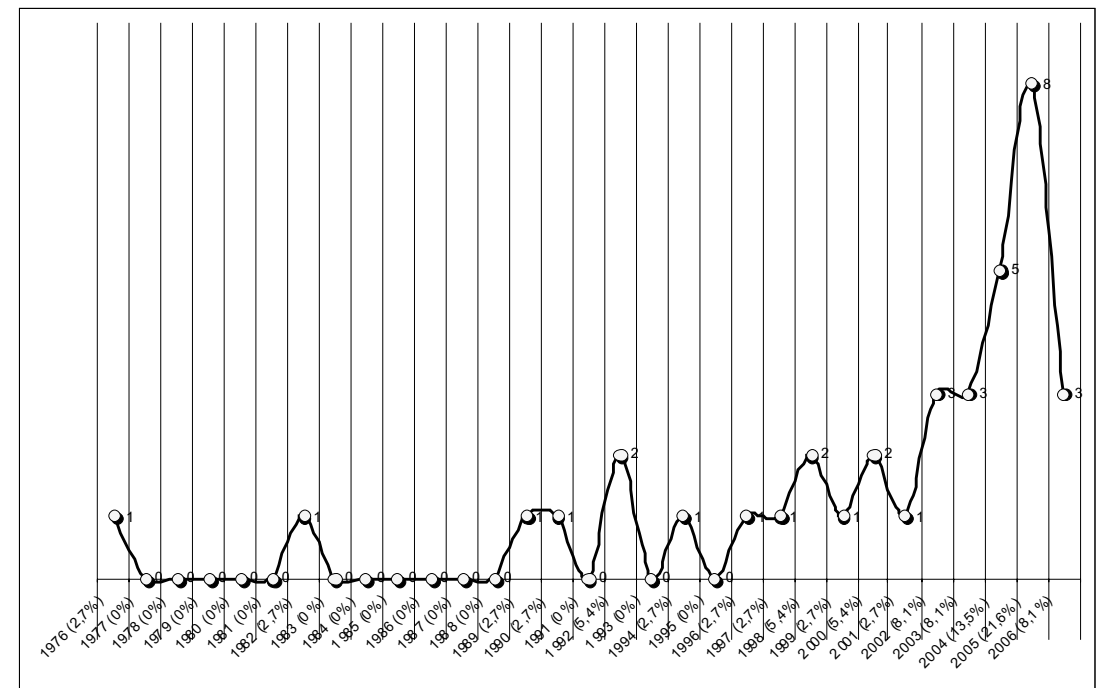

Figura 4. Distribuição de artigos sobre ética por ano de publicação. Fonte: As autoras, de acordo com Base BRAPCl.

Essa dimensão, povoada pelas rápidas transformações do mundo globalizado, como diria Guimarães (2000, p.65), incita o profissional a posturas condizentes com os compromissos sociais, "compromissos esses que propiciarão a constante construção e aperfeiçoamento da profissão pela sua própria coletividade" e que se referem a cinco instâncias ov entidades distintas, apontadas pelo autor: "o usuário, a organização, a informação, a profissão e $O$ eu mesmo". Tais instâncias fazem-se presentes no corpus analisado, como a reiterar a idéia de que as condições estruturais determinam relações e posturas dos seres humanos na conjuntura em que atuam, desenvolvem seu trabalho e constroem sua cultura.

\section{CONSIDERAÇÕES FINAIS}

Na atual conjuntura, que enseja o debate sobre os direitos humanos, delineia-se um caminho fértil para se enfrentar a dramática e contraditória convivência entre a transformação da ciência e da tecnologia em forças produtivas, por um lado, e as necessidades de ampliação dos benefícios sociais, por outro.

O que resulta como síntese das preocupações representadas pelos artigos sobre ética identificados no corpus acena para o esclarecimento das relações entre a autonomia dos saberes e práticas institucionalizadas e a dos indivíduos, entre liberdade pessoal e política, entre competição e cooperação social, entre as formas 
de domínio e a passividade diante dos crimes cometidos em nome de valores instituídos.

Essas contradições expressam-se na produção científica analisada, revelando o crescimento da consciência de que o processo de formação não se reduz à transmissão de conhecimentos, mas se volta à construção da consciência crítica. Apóia-se na convicção de que é possível a construção de conhecimentos e raciocínios fundamentais ao desenvolvimento humano, mas, acima de tudo, acredita no exemplo, na práxis, na investigação da realidade e na luta por uma sociedade mais justa e por seres humanos mais altruístas.

Pergunta-se, portanto, se, apesar dos efeitos da globalização da economia e cultura mercantis, há esperança de sobrevivência do sujeito moral autônomo, capaz não somente de ordenar a ação, mas de dominar a reação. Do sujeito que se fundamenta no critério da igualdade de direitos e deveres, num universo em que o caráter pragmático e utilitário das relações com a natureza e com o outro tende a tornar-se o horizonte do pensar e do sentir.

As inquietações relacionadas com a educação comparecem, explícita ou implicitamente, como questão de fundo nos artigos analisados, seja como preocupação voltada ao trabalho, ou à cultura organizacional, ou à incorporação de novas tecnologias à ação profissional. Repensar os caminhos percorridos pelo pensamento e ação humanos em prol de uma vida digna, confrontando-os com as exigências de reflexão e renovação, impõe-se na conjuntura atual aos estudiosos da sociedade e, de modo especial, aos educadores.

\section{REFERÊNCIAS}

ALVES, G. Nova ofensiva do capital, crise do sindicalismo e as perspectivas do trabalho: o Brasil nos anos noventa. In: TEIXEIRA, F.J.S.; OLIVEIRA, M.A. (Org.). Neoliberalismo e reestruturação produtiva: as novas determinações do mundo do trabalho. São Paulo: Cortez; Fortaleza: UECE, 1996. p.109-161.

BADIOU, A. Ética: um ensaio sobre a consciência do mal. Rio de Janeiro: Relume Dumará, 1995.

CHRÉTIEN, C. A ciência em ação: mitos e limites. Campinas, Papirus, 1994

DUPAS, G. Ética e poder na sociedade da informação. 2.ed. São Paulo: Unesp, 2001.

GUIMARÃES, J.A.C. O profissional da informação sob o prisma de sua informação. In: VALENTIN, M.L.P. (Org.). O profissional da

informação: formação, perfil, e atuação profissional. São Paulo: Polis, 2000. p.53-70.

MCLAREN, P. A vida nas escolas: uma introdução à pedagogia crítica nos fundamentos da educação. 2.ed. Porto Alegre: Artmed, 1997.

OLIVEIRA, M.A. A nova problemática do trabalho e a ética. In: TEIXEIRA, F.J.S.; OLIVEIRA, M.A. (Org.). Neoliberalismo e reestruturação produtiva: as novas determinações do mundo do trabalho. São Paulo: Cortez; Fortaleza: UECE, 1996. p.163-194.

SCHAFF, A. A sociedade informática: as conseqüências sociais da segunda revolução industrial. 4.ed. São Paulo: Unesp, 1993. 